\title{
PET/CT in South Africa: a lost cause?
}

In the previous issue of the SA Journal of Radiology, ${ }^{1}$ the Editor-in-chief of the journal expressed serious concerns about the future of positron emission tomography (PET) in South Africa - and not without reason. Business Day on 4 September 2008 reported that 'High-tech scan centres look set to sink.'. According to this article, South Africa's private PETCT scanning centres are struggling to recoup their multi-million-Rand investments. This is happening in spite of international sentiments expressed regarding the 'unparalleled contribution of F-18 FDG PET to medicine over 3 decades. ${ }^{3}$ PET-CT is battling to establish itself in South Africa, notwithstanding numerous reports confirming the costeffectiveness of this modality by virtue of inter alia obviating unnecessary surgical procedures and ineffective chemotherapy regimens. The question of why this situation has developed in South Africa should be investigated.

PET using the glucose analogue F-18 FDG was first introduced in the late 1970s. If we look back at the history of PET in South Africa, interest in obtaining PET systems first arose in the mid-1980s. These efforts were discontinued with the political changes taking place in South Africa and the new government's initial emphasis on primary medicine. Although there had been marked growth in the use of PET worldwide since its inception, South Africa lagged behind in acquiring PET cameras. It was only after the development of PET-CT machines that there was renewed interest in this technology, not only from nuclear physicians but also from radiologists; this eventually led to the installation of the first PET-CT system in Johannesburg in late 2005.

Because of strong interest in this modality, the South African PET Users Association $\left(\right.$ SAPUA $^{4}$ ) was established in December 2004, under the auspices of the South African Society of Nuclear Medicine. Members of SAPUA include nuclear physicians, medical physicists, radiographers, other scientists and colleagues from the industry. There has, however, been limited utilisation of SAPUA by the many groupings involved with PET, including the radiology community.

In 2005, SAPUA performed a needs analysis for PET in South Africa because serious concerns had been expressed about the possibility of oversupply and/or maldistribution of facilities, if the technology were introduced in a piecemeal fashion. Using data from the National Cancer Registry, it was predicted that between 5 and 7 facilities should initially be established to service both the private and public sectors, with a subsequent review to determine whether additional facilities were required. ${ }^{5}$ SAPUA suggested that in some regions, facilities should be shared between public and private practices.

Despite this needs analysis, the installation of PET-CT facilities suddenly boomed in South Africa. Six PET-CT facilities are currently operational in the private sector, of which 3 are in Gauteng, and there are currently 3 in public hospitals. The first private PET-CT facility was established in Johannesburg in 2005, with most of the others following in 2006. Despite warnings about the number of PET facilities, it seems that there was minimal consultation between the various groupings, and no consultation between the public and private sectors regarding the location or use of these facilities.

Another grave concern is the current geographical and socio-economic maldistribution of PET-CT facilities, with the unavailability of this service to a large number of South Africans, especially those who cannot afford high-tech medical care. The gross under-utilisation of the existing facilities is unacceptable in a resource-poor country like South Africa.

According to the report in Business Day, medical aid schemes are to blame for this situation, as they either refuse to pay for PET-CT scans, or put too many bureaucratic hurdles in the way. The question can be asked whether they should be entirely blamed for taking such an approach. There is no doubt that PET is an expensive modality. The two components that make up the cost of PET-CT studies are the cost of the equipment and the cost of the radiopharmaceutical (F-18 FDG). A recent report by the USA Department of Health and Human Services analysed, among other factors, the increase in 'advanced imaging' procedures; $^{6}$ these included PET. According to this report, PET imaging accounted for about only $5 \%$ of the growth in services, but for more than $18 \%$ of the growth in allowed charges. Without controls, the same trend in expenditure for PET-CT services as in the USA would probably occur in South Africa. It is therefore understandable that medical aid schemes acted cautiously.

However, medical aid schemes need to accept the reality of the important contribution that PET-CT currently makes to the management of many cancer patients. They also need to look beyond the cost of a PET-CT scan on its own. In many cases, the expense of a PET-CT scan will be outweighed by the savings that follow correct diagnosis, staging, and evaluation of treatment, as provided by the scan.

Suppliers of FDG should also look critically at the cost of this radiopharmaceutical. While there is a risk in lowering the price, this needs to be weighed against the possibility of increasing the number of patients scanned, and even preventing the possibility of PET-CT practices having to close their doors.

Is there a way forward? Should struggling practices close their doors and sell their PET-CT cameras? At present, only a minority of South Africans have access to PET-CT. Now is the time for the nuclear medicine and radiology communities utilising PET in South Africa to stand together and save this modality for the people of the country. With optimal collaboration between practices and public health facilities, so that both public and private patients can share the benefits of this modality, the cameras will be used more cost-effectively, and oncology patients especially will benefit. Medical aid schemes will also benefit, as unnecessary surgery in patients who are upstaged will be obviated, and the administration of futile chemotherapy regimens stopped timeously in patients who do not respond to the therapy.

\section{Annare Ellmann}

President: World Federation of Nuclear Medicine and Biology

1. Lotz J. PET-CT meltdown is looming (Editorial). S Afr J Radiol 2008; 12: 26

2. Kahn T. High-tech scan centres look set to sink. Business Day 4 Sept 2008. http://www.businessday.co.za Articles/TarkArticle.aspx?ID=3314642 (accessed 4 October 2008).

3. Basu S, Alavi A. Unparalleled contribution of F-18 FDG PET to Medicine over 3 decades. J Nucl Med 2008; 49(10): Newsline 17N.

4. SAPUA website. www.sasnm.com/SAPUA.htm (accessed 4 October 2008).

5. SASNM website. www.sasnm.com/National_Strategy_Discussion_Document_final.pdf (accessed 5 October 2008).

6. Growth in advanced imaging paid under the Medicare physician fee schedule. Boston, USA: Departmen of Health and Human Services. http://oig.hhs.gov/oei/reports/oei-01-06-00260.pdf (accessed 6 October 2008) 